\title{
Erratum to: Prediction of Surface Flow by Forcing of Climate Forecast System Reanalysis Data
}

\author{
Milad Jajarmizadeh ${ }^{1}$ - Lariyah Mohd Sidek ${ }^{1}$ • \\ Majid Mirzaei $^{2} \cdot$ Sina Alaghmand ${ }^{3}$ - Sobri Harun ${ }^{4}$. \\ Mohammad Rafee Majid ${ }^{5}$
}

Published online: 1 June 2016

(C) Springer Science+Business Media Dordrecht 2016

\section{Erratum to: Water Resour Manage \\ DOI 10.1007/s11269-016-1303-0}

Due to an oversight, one of the author's names was misspelt in the original publication. The correct name is as follows: Majid Mirzaei. The name has been corrected in the online publication (and shows correctly in this erratum).

The online version of the original article can be found at http://dx.doi.org/10.1007/s11269-016-1303-0.

Milad Jajarmizadeh

milad_jajarmi@yahoo.com

1 Department of Civil Engineering, Universiti Tenaga Nasinal Malaysia, 43000 Kajang, Selangor, Malaysia

2 Faculty of Engineering and Science, Universiti Tunku Abdul Rahman, Kuala Lumpur, Malaysia

3 Discipline of Civil Engineering, School of Engineering, Monash University Malaysia, Bandar Sunway, Selangor, Malaysia

4 Department of Hydraulics and Hydrology, Faculty of Civil Engineering, Universiti Teknologi Malaysia, 81310 Skudai, Johor, Malaysia

5 Centre for Innovative Planning and Development (CIPD), Department of Urban and Regional Planning, Universiti Teknologi Malaysia, 81310 Skudai, Johor, Malaysia 